\title{
Current Terminology of Pelvic Floor Dysfunctions
}

\section{Kadınlarda Pelvik Taban Bozukluklarının Güncel Terminolojisi}

(i) Büşra YILMAZ, iD Ergül ASLAN

İstanbul University-Cerrahpaşa Florence Nightingale Faculty of Nursing, Department of Women’s Health and Gynecologic Nursing, İstanbul,

Turkey

\section{ABSTRACT}

Pelvic floor disorders (PFD) affect the quality of life of millions of people worldwide. PFD, which increase in frequency with advancing age, affect not only the individual with the symptoms but also the family, caregivers and the society. Increased diagnostic methods and applications in treatment cause complexity in symptom terminology. For this reason, international organizations dealing with PFD have been working for updating definitions and/or adding new definitions for many years. Accordingly, the symptoms of PFD are; urinary, pelvic organ prolapse, sexual dysfunction, lower urinary tract pain and/or other pelvic pain and anorectal dysfunction. In the diagnosis and treatment stages of PFD and in studies, expressing the symptoms in a common language is very important for achieving standardization. Standardization in terminology will provide consensus and increase the success of treatment and prevention of PFD symptoms. The aim of this review is to examine the standardized current terminology of the symptoms of PFD in the light of the literature.

Keywords: Pelvic floor disorder, symptom, standardized terminology, female

\section{ÖZ}

Pelvik taban bozuklukları (PTB) dünya genelinde milyonlarca kişinin yaşam kalitesini etkiler. İlerleyen yaşla sıklığı artan PTB yalnızca semptomu olan bireyi değil ailesini, bakım verenleri ve toplumu etkiler. Tanılama yöntemlerinin ve tedavide uygulamaların artması semptom terminolojisinde de karmaşıklığa sebep olmaktadır. Bu sebeple PTB ile ilgilenen uluslararası kuruluşlar uzun yıllardır tanımların güncellenmesi ve/veya yeni tanımların eklenmesi amacıyla çalışmalar yürütmektedir. $\mathrm{Bu}$ doğrultuda PTB semptomları; üriner, pelvik organ prolapsusu, cinsel işlev bozukluğu, alt üriner sistem ağrısı ve/veya diğer pelvik ağrı ve anorektal disfonksiyon olarak gruplandırılmıştır. PTB'nin tanı ve tedavi aşamalarında ve araştırmalarda semptomların ortak bir dille ifade edilmesi standardizasyon sağlanabilmesi açısından oldukça önemlidir. Terminolojide standardizasyon fikir birliğini sağlayarak pelvik taban bozukluğu semptomlarının tedavisi ve önlenmesinde başarıyı artıracaktır. Bu derlemenin amacı PTB semptomlarının standardize güncel terminolojisini literatür doğrultusunda incelemektir.

Anahtar Sözcükler: Pelvik taban bozukluğu, semptom, standardize terminoloji, kadın
Address for Correspondence: Büşra YILMAZ, İstanbul University-Cerrahpaşa Florence Nightingale Faculty of Nursing, Department of Women's Health and Gynecologic Nursing, İstanbul, Turkey E-mail: ylmzbsr678@gmail.com ORCID ID: orcid.org/0000-0001-6937-5351
Received: 24.05 .2020

Accepted: 06.01.2021

Cite this article as: Yılmaz B, Aslan E. Current Terminology of Pelvic Floor Dysfunctions. Bezmialem Science 2021;9(2):236-43. 


\section{Introduction}

Urinary, genital and intestinal systems located in the pelvic floor are intricately linked with each other in terms of anatomical structure and function. The striated muscles of the pelvic floor together with their fascial connections prevent the displacement of the pelvic organs, maintain urinary and fecal control, provide dynamic support, increase satisfaction in sexual life, and create a driving force in the expulsion phase of normal birth (1). The pelvic floor, which is desired to continue its life-long functions without any problems, may be insufficient to maintain its function for some reasons. Female gender, Caucasian race, low education level, excessive caffeine and cigarette consumption, obesity, difficult and traumatic birth, advanced age and postmenopausal period are among the main factors that disrupt the pelvic floor structure. Other factors that disrupt the pelvic floor muscle structure are chronic cough, chronic constipation, multiple sclerosis, diabetes, joint problems, connective tissue weakness, previous pelvic surgery, hysterectomy and urinary tract infection. The most important features of pelvic floor disorders (PFD) are the pelvic floor muscles being loose or tense than normal, pelvic pain and increased or decreased sensitivity. In the clinic, symptoms are grouped by associating them with complaints such as urinary/fecal incontinence, defecation problems, pelvic organ prolapse (POP), sexual dysfunction, chronic pelvic pain, and vulvodynia (2). Mortality rates associated with PFD are not high, but problems such as POP, pelvic organ dysfunction, dyspareunia, back pain, sexual dysfunction and decreased sexual satisfaction cause a decrease in the quality of life of women (3). In addition, PFD treatment brings a significant financial burden for individuals and public resources. It is estimated that more than one billion dollars are spent annually on the treatment of PFDs in the United States of America (4). Although PFDs are common all over the world, they cannot be adequately addressed due to both the delay in the admission of the patient and the lack of standard criteria for diagnosis (5). Increasing and complexity of definitions, diagnosis and treatment methods related to the symptoms of PFDs increased the need for new terminologies. Lack of standardization in the diagnostic criteria of PFDs and the use of their own definitions by centers may cause ambiguity in terminology, confusion and interdisciplinary communication gaps (6). It is very important to standardize the definitions of PFD symptoms in the diagnosis and treatment process of PFD and in studies conducted. This standardization is beneficial in providing language and notion consensus, and increases the success in diagnosis, treatment, and prevention of symptoms in PFD (5). The International Continence Society has pioneered the standardization of the definitions of PFD symptoms for many years. The terminology reports of the Standardized Terminology Committee published in 1988 and 2002 are among the first examples in this field $(7,8)$. As a result of the joint studies of the International Urogynecological Association and the International Continence Association, a joint report on the terminology for female pelvic floor dysfunction was published in 2010 (9). As a result of the joint efforts of the International Consultation on Urological Diseases and the International Continence Association, the terminology of symptoms, diagnosis and treatment processes related to urinary incontinence and fecal incontinence were updated with the title of "incontinence" in 2017 (10).

The purpose of this review is to examine the current standardized terminology of PFD symptoms in accordance with the literature.

\section{Standardized Terminology for Symptom Groups of Pelvic Floor Disorder}

Symptom is a sign of a health problem or disease perceived by the woman as a deviation from normal in structure, function, perception or experience. Symptoms either occur spontaneously or are subjective data reported by the individual and/or the caregiver. Symptom groups are urinary symptoms, lower urinary tract pain and/or other pelvic pain, urinary tract infection, POP, sexual dysfunction, and symptoms of anorectal dysfunction $(9,11)$. While some definitions remained the same in the updating phase of the terminology of PFD symptoms in the literature, some definitions were highlighted with the expressions "new", "updated" or "changed". Table 1 includes definitions regarding the current terminology of PFDs in women.

\section{Conclusion}

Increasing diagnosis and treatment methods in PFDs have caused the symptom terminology to become complex. For this reason, organizations such as the International Continence Association, the International Urogynecology Association, the European Association of Urology, the American Urology Association and the Canadian Urology Association carry out studies and publish reports on updating and standardizing the terminology of pelvic dysfunction symptoms. The use of common terminology in expressing the symptoms of PFDs is very important in terms of standardization. In this review, which deals with the current terminology of pelvic dysfunction symptoms, existing, newly added, amended and updated definitions of symptoms are included. These definitions will be added in future studies and will play a facilitating role in the understanding of the terminology to be updated. 
Table 1. Definitions for current terminology of pelvic floor disorders in women

1. Urinary symptoms: Urinary symptoms are divided into three groups as those related to urine storage, those related to urinate, and postmicturition symptoms (11).

1.1. Storage symptoms: They are the lower urinary tract symptoms that occur during the storage phase of the bladder (New) (11).

1.1.1. Increased urinary frequency: It is the occurrence of urinary sensation more frequently than is considered normal by the individual/caregivers. Time of day and number of urination are not specified (New) (11).

Polyuria: It is defined as a significantly higher amount of urine within 24 hours than its previous state (New) (12).

\section{Sensory symptoms}

1.1.2. Bladder filling/sensory symptoms: They are abnormal findings during bladder filling (New) (13).
Increased daytime urinary frequency: It is the expression that urination occurs more frequently during waking hours than is considered normal by the individual/caregivers (Changed) (11).

Nocturia: It is one or more waking complaints for the need to urinate. The patient continues to sleep after each urination. This symptom should be measured using the bladder diary (Same) (11).

Diurnal polyuria: It is markedly higher amount of daytime urine compared to its previous state (New) (12).

Nocturnal polyuria: It is significantly higher amount of nighttime urine compared to the previous situation (New) (12).

Increased bladder filling sensation: It is the complaint of bladder filling sensation being more intense and long-lasting than before. This is different from urgency in that it can be delayed in a busy state despite the feeling of bladder filling sensation (Modified) (13).

Urgency: It is a difficult, sudden and compelling urge to urinate (Same) (13).

Reduced bladder filling sensation: The feeling of bladder filling is less intense and longer in duration than before (Changed) (11).

Absent bladder filling sensation: It is the coexistence of both the lack of bladder filling sensation and the inability to empty the bladder completely (Same) (7).

Non-specific (atypical) bladder filling sensation (bladder dysesthesia): It is a complaint of abdominal distension, vegetative (involuntary) nausea, vomiting, pallor, or abnormal bladder filling sensation such as spasticity (7).

Urinary incontinence symptoms

Urinary incontinence: It is involuntary urinary incontinence (Same) (11).

Urgency urinary incontinence: It is involuntary urinary incontinence associated with sudden urgency (Same) (11).

Stress urinary incontinence is involuntary incontinence while coughing, sneezing, including sportive activities. In some languages, the expression "activity-related incontinence" may be preferred in order to prevent confusion with mental stress (Same) (11).

Mixed urinary incontinence: It is the coexistence of urinary incontinence complaints due to stress and sudden urgency (Same) (11).

Enuresis: It is an intermittent complaint of urinary incontinence while asleep (Changed) (12).

Continuous urinary incontinence: It is involuntary continuous incontinence (Changed) (12).

Insensible urinary incontinence: It is the situation in which the individual knows that urinary incontinence has occurred but does not realize how and when it has occured (Changed) (12).

Postural urinary incontinence: The complaint of urinary incontinence during posture or position change, for example, urinary incontinence in the lying or sitting position (New) (12).

Disability associated incontinence: It is urinary incontinence caused by inability to reach the toilet in time due to orthopedic, neurological and/or mental disorders (New) (14).

Overflow incontinence: It is urinary incontinence associated with excessive filling of the bladder, although it does not have a defined cause (New) (14).

Sexual arousal incontinence: It is involuntary incontinence during sexual arousal, foreplay, and/ or masturbation (New) (14).

Climacturia: It is involuntary incontinence during orgasm (New) (14).

Overactive bladder syndrome: It is a sudden sensation of urgency, frequent urination during the day, nocturia at night, without urinary tract infection or other detectable pathologies.

Complaints are not necessarily accompanied by urinary incontinence (Changed) (11).

1.2. Voiding symptoms: The presence of lower urinary tract symptoms during the voiding phase (Experienced during urination) (New) (15). 
Table 1. Continued

Hesitancy: It is a complaint of delay in initiating urination (Modified) (9).

Paruresis "bashful" or "shybladder": It is a problem in initiating urination when next to other people, although there is no difficulty in urinating while alone (New) (16).

Episodic inability to void: It is occasional difficulty in initiating urination despite attempts such as increasing abdominal pressure, valsalva maneuver and/or suprapubic compression (New) (9).

Slow urinary stream: It is when the flow of urine becomes slower than before or the realization that the flow of urine is slow compared to other people (Same) (9).

Intermittency: It is the stopping of urine flow one or more times and starting again during urination (Same) (11).

Terminal dribbling: It is the transformation of urine flow to drip in the last part of urination (Modified) (11).

Spraying (splitting) of urinary stream: It is the spraying of urine rather than direct full flow while urinating (11).

Position-dependent voiding: It is the individual's adoption of unique positions such as a sitting position to urinate (New) (11).

Dysuria: It is sensation of pain, burning and other symptoms during urination (Changed) (11).

Stranguria: It is generally characterized by pain-related, slow, difficult and spasmodic (drop by drop) urination (New) (11).

Hematuria: It is the appearance of blood in the urine when starting to urinate, during or at the end of urination.

Pneumaturia: It is the sensation of gas/air presence in the urethra during or after urination (New) (11).

Fecaluria: It is the presence of feces in the urine (New) (11).

Albiduria (Chyluria): It is the presence of chilus (pale/white, milky liquid) in the urine (New) (11).

Urinary retention: It is the inability to empty the bladder completely (New) (11).

Acute urinary retention: It is generally characterized by a painful bladder, and the inability to urinate despite intense effort even though the bladder is full (New) (11).

Chronic urinary retention: It is a chronic/recurrent feeling of inability to empty the bladder. This situation may cause urinary incontinence and bladder globe (New) (11).

1.3. Post-voiding symptoms: They are lower urinary tract symptoms experienced after urinating (New) (16).

Feeling of incomplete bladder emptying: It is the feeling that the bladder cannot be emptied completely after urinating (Changed) (11).

Need to immediately re-void "encore or double voiding": It is the need to urinate again immediately after urinating due to interruption of urine flow (Changed) (11).

Post-voiding incontinence: It is involuntary urinary incontinence after the completion of urination (New) (11).

Post-micturition urgency: It is the feeling of urgency after urinating (New) (11).

\section{Lower urinary tract pain and/or other pelvic pain}

Pain: It is a very uncomfortable feeling defined by the patient as pressure or discomfort. Pain is defined according to region, type, frequency, duration, and factors that increase or decrease pain (Changed) (17).

Bladder pain: It is generally characterized by suprapubic or retropubic pain as a result of pressure caused by bladder filling. Pain may persist after the bladder is emptied or relief can be achieved (Modified) (7).

Urethral pain: It is a complaint of pain, pressure or discomfort in the urethra before, during and/or after urination (Modified) (7).

Pelvic pain: It is a complaint of pain, pressure, or discomfort related to the pelvis. Pain has no direct connection with the bladder, urethra or perineal region (Same) (7).

Anorectal pain symptoms: They are complaints of pain, pressure, or discomfort, especially when defecating or straining. Pain can also occur at any time (New) (18).

Pain during straining/defecation: It is feeling pain during defecation or straining (Same) (18).

Inflammatory anorectal pain: It is pain in the anorectal region characterized by burning (New) (18).

Non-inflammatory anorectal pain: It is blunt anorectal pain (due to pain in the rectal area, levator ani syndrome, pudendal nerve compression) (New) (18).

Coccygeal pain (coccydynia): It is a complaint of pain, pressure or discomfort in the coccygeal region (New) (18).

Pudendal pain (neuralgia): It is a complaint of pain, pressure or discomfort caused by infection of the pudendal nerve (Changed) (18).

Chronic pelvic pain syndrome: It is characterized by persistent pain for more than six months or recurrent attacks of abdominal / pelvic pain. There is a feeling of hypersensitivity and discomfort in the elimination changes and may be accompanied by sexual dysfunction (Same) (18). 
Table 1. Continued

\section{Urinary tract infection}

Symptoms of acute urinary tract infection: Symptoms of increased bladder sensitivity, urgency, increased urination frequency and dysuria accompanied or not accompanied by sudden urinary incontinence may cause urinary tract infection. The presence of some microorganisms in the urine and evidence of pyuria are required for the confirmation of urinary tract infection (Modified) (11).

Recurrent urinary tract infections: Diagnosis of at least 2 urinary tract infection in the last 12 months in the presence of symptoms in the history. In order to diagnose a new urinary tract infection, previous urinary tract infections must be treated (Modified) (11).

Urethral discharge: It is pus, mucus or bloody discharge coming from the urethral meat (New) (11).

\section{Pelvic organ prolapse (POP) Symptoms}

Findings expressed differently from normal in terms of feeling, structure or function in the area where the pelvic organs are located by the woman. Symptoms are aggravated by prolonged standing or after exercise, such as when gravity is effective, and decreases when lying on the back. Prolapse is more pronounced in conditions where abdominal pressure increases, such as defecation (9).

Vaginal bulging: It is a feeling of "something coming down" or bloating in the vagina. The woman may state that she can realize the swelling by feeling it directly with her hand or see it with the help of a mirror (Same) (9).

Pelvic pressure: It is the feeling of increased weight or pulling downward in the suprapubic region and/or pelvis (Same) (9).

Bleeding, discharge, infection: Presence of vaginal bleeding, discharge or infection due to prolapse ulceration (Same) (9).

Low backache: It is the complaint of temporary pain in the sacral or back region associated with pelvic organ prolapse (Same) (9).

5. Symptoms of anorectal dysfunction: They are grouped as incontinence, storage, sensory, during or after defecation, prolapse, pain, sexual dysfunction and other anorectal symptoms in the anorectal region (Same) (14).

\subsection{Anorectal incontinence symptoms}

5.2.Anorectal storage symptoms
Anal incontinence: It is involuntary stool or gas leakage (Same) (14).

Fecal incontinence: It is involuntary incontinence of solid or liquid fecal matter (Same) (14).

Flatus Incontinence: It is involuntary gas leak (Same) (14).

Double incontinence: Coexistence of anal and urinary incontinence complaints (New) (14).

Coital fecal incontinence: It is fecal incontinence during vaginal penetration (New) (14).

Passive fecal leakage: It is involuntary incontinence of solid or liquid stool without warning/feeling of contamination (New) (14).

Overflow fecal incontinence: It is leakage of stool in the intestine (New) (14).

Increased daytime defecation: It is the statement that defecation occurs more frequently during waking hours than is considered normal by the woman (New) (14).

Nocturnal defecation: It is the interruption of sleep one or more times with the need to defecate (New) (14).

Fecal urgency: It is a sudden and compulsive urge to defecate and difficulty in delaying defecation (Same) (14).

Fecal urgency warning time: It is the time from the first feeling of urgency to voluntary defecation or fecal incontinence (Same) (14).

Fecal/flatal urgency incontinence: It is fecal urgency and involuntary stool/gas leakage (Same) (14).

Tenesmus: It is the desire to empty the bowels with frequent pain, cramping, and a feeling of tension in the rectum without stool (New) (14).

Coital fecal urgency: It is the sensation of bowel movement during vaginal intercourse (New) (14). 
Table 1. Continued

\subsection{Anorectal sensory symptoms}

\subsection{Symptoms during or after defecation}

\subsection{Symptoms of anorectal prolapse}

\subsection{Anorectal pain symptoms}

\subsection{Symptoms of anorectal sexual dysfunction}

Diminished rectal sensation: It is the decrease in sensation in the rectum (Same) (14).

Increased rectal sensation: It is the increase in the desire to defecate during rectal filling compared to the previous (New) (14).

Constipation: It is infrequent bowel movements and/or absence of them. It is the need for frequent straining for defecation or digitization for defecation (Updated) (14).

Slow transit: It is the decrease in bowel movements due to the delay in the arrival of stool to the rectum (Same) (14).

Obstructed defecation: It is difficulty during defecation (Same) (14).

Feeling of incomplete bowel evacuation: It is the feeling that the bowels are not emptied completely after defecation and the desire to defecate again (Same) (14).

Straining to defecate: It is exerting intense effort with abdominal straining or valsalva to initiate, maintain or improve defecation (Same) (14).

Sensation of blockage: It is the presence of complaints suggesting anorectal occlusion (New) (14).

Digitation: It is the finger manipulation of the rectum or vagina to assist in the evacuation of stool contents (New) (14).

Rectal digitation: It is to support the rectum with a finger to help defecation (Same) (14).

Vaginal digitation: It is the use of thumbs or other fingers through the vaginal route to aid defecation (Same) (14).

Splinting: It is to manually support the perineum or buttocks, usually with thumbs or fingers, to aid defecation (New) (14).

Post defecatory soiling: It is contamination/spotting that occurs after defecation (New) (14).

Anorectal prolapse: It is a complaint of a "bulge" or feeling of "something descending" through the anus/rectum. The woman can either feel the swelling directly by hand or see it with the help of a mirror (Updated) (10).

Pain during straining/defecation: It is the feeling of pain during defecation or straining (Same) (10).

Inflammatory anorectal pain: It is a burning and/or itching sensation in the anorectal region caused by fissure, inflammation or sepsis (Same) (10).

Non-inflammatory anorectal pain: It is a complaint of blunt anorectal pain due to reasons such as proctalgia fugax, levator ani syndrome, pudendal neuralgia (Same) (10).

Symptoms of sexual dysfunction: They are the different feelings and/or functions of the woman felt during sexual activity (Same) (10).

Female sexual dysfunction: It is pain or dysfunction during sexual desire, arousal, orgasm or penetration (Same) (10).

Dyspareunia: It is a continuous or recurrent complaint of pain/ discomfort associated with vaginal penetration attempt or full penetration (Same) (9).

5.8. Superficial (introital) dyspareunia: It is the feeling of pain or discomfort at the vaginal entrance during sexual intercourse (Same) (9). 5.9. Deep dyspareunia: In severe penetration, it is the complaint of pain/discomfort in the middle or upper vagina (Same) (9). 
Table 1. Continued

5.10. Obstructed intercourse: It is a situation in which vaginal penetration is prevented due to any obstruction (Same) (9).

5. 11. Vaginal laxity: Complaints caused by the laxity of the vagina (Same) (9).

5.12. Other anorectal symptoms
Anal intercourse: It is the penetration of the erectile penis into the anus (New) (19).

Other anal sexual practices with body parts: They are the stimulation of the anus and/or rectum by the individual herself or her partner in order to obtain sexual pleasure with other body parts (e.g. finger, fist) other than the penis (Same) (19).

Other anal sexual practices with inanimate objects: They are the stimulation of the anus and/or rectum by the individual herself or her partner to obtain sexual pleasure with inanimate objects (e.g. dildo) (Same) (19).

Anodyspareunia: It is a complaint of pain or discomfort occurring during or during anal penetration attempt (New) (19).

Anal laxity: It is a feeling of laxity in the anal tone (New) (19).

Rectal bleeding/mucus: It is blood or mucus coming from the rectum (Same) (19).

Perianal itching/pruritus: It is the sudden presence of itching in the perianal area (New) (19).

Flaturia: It is gas leakage from the urethra (New) (19).

Fecaluria: It is fecal incontinence from the urethra (New) (19).

Vaginal flatus/feces: It is leakage of gas or stool from the vagina (New) (5).

assessment of sexual health of women with pelvic floor dysfunction. Int Urogynecol J 2018;29:647-66.

6. Bo K, Frawley HC, Haylen BT, Abramov Y, Almeida FG, Berghmans B, et al. An International Urogynecological Association (IUGA)/International Continence Society (ICS) joint report on the terminology for the conservative and nonpharmacological management of female pelvic floor dysfunction. Neurourol Urodyn 2017;36:221-44

7. Abrams P, Blaivas JG, Stanton SL, Andersen JT. The standardisation of terminology of lower urinary tract function. The International Continence Society Committee on Standardisation of Terminology. Scand J Urol Nephrol Suppl 1988;114:5-19.

8. Abrams P, Cardozo L, Fall M, Griffiths D, Rosier P, Ulmsten U, et al. The standardisation of terminology of lower urinary tract function: report from the Standardisation Sub-committee of the International Continence Society. Neurourol Urodyn 2002;21:167-78.

9. Haylen BT, de Ridder D, Freeman RM, Swift SE, Berghmans $\mathrm{B}$, Lee J, et al. An International Urogynecological Association (IUGA)/International Continence Society (ICS) joint report on the terminology for female pelvic floor dysfunction. Neurourol Urodyn 2010;29:4-20.

10. Milsom I. Epidemiology of urinary incontinence (UI) and other lower urinary tract symptoms (LUTS), pelvic organ prolapse (POP) and anal (AI) incontinence. In Paul A, Linda W, Alan W, editors. Incontinence. Tokyo: 6th International Consultation on Incontinence; 2017.p.1-74. 
11. D’Ancona C, Haylen B, Oelke M, Abranches-Monteiro L, Arnold E, Goldman H, et al. The International Continence Society (ICS) report on the terminology for adult male lower urinary tract and pelvic floor symptoms and dysfunction. Neurourol Urodyn 2019;38:433-77.

12. Hashim H, Blanker MH, Drake MJ, Djurhuus JC, Meijlink J, Morris V, et al. International Continence Society (ICS) report on the terminology for nocturia and nocturnal lower urinary tract function. Neurourol Urodyn 2019;38:499-508.

13. Lowder JL, Bavendam TG, Berry A, Brady SS, Fitzgerald CM, Fok CS, et al. Terminology for bladder health research in women and girls: Prevention of Lower Urinary Tract Symptoms transdisciplinary consortium definitions. Neurourol Urodyn 2019;38:1339-52.

14. Sultan AH, Monga A, Lee J, Emmanuel A, Norton C, Santoro G, et al. An International Urogynecological Association (IUGA)/International Continence Society (ICS) joint report on the terminology for female anorectal dysfunction. Int Urogynecol J 2017;28:5-31.

15. Gajewski JB, Schurch B, Hamid R, Averbeck M, Sakakibara R, Agrò EF, et al. An International Continence Society (ICS) report on the terminology for adult neurogenic lower urinary tract dysfunction (ANLUTD). Neurourol Urodyn 2018;37:1152-61.

16. Hambrook D, Taylor T, Bream V. Cognitive Behavioural Therapy for Paruresis or "Shy Bladder Syndrome": A Case Study. Behav Cogn Psychother 2017;45:79-84.

17. Stedman's Medical Dictionary. 28th ed. Baltimore, USA: Lippincott, Williams and Wilkins, 2006.

18. Doggweiler R, Whitmore KE, Meijlink JM, Drake MJ, Frawley $\mathrm{H}$, Nordling J, et al. A standard for terminology in chronic pelvic pain syndromes: A report from the chronic pelvic pain working group of the international continence society. Neurourol Urodyn 2017;36:984-1008.

19. Toozs-Hobson P, Freeman R, Barber M, Maher C, Haylen B, Athanasiou S, et al. An International Urogynecological Association (IUGA)/International Continence Society (ICS) joint report on the terminology for reporting outcomes of surgical procedures for pelvic organ prolapse. Neurourol Urodyn 2012;31:415-21. 